\title{
Design and Learning Strategies Applied in Mooc: A Meta-Analysis
}

\author{
Babakura Mammana, Azizah Yusofa, Hassan M M AbuHassna ${ }^{a}$, Hanan Alya, Turki Al-Ahmadia, Noor Azean Atanª, Jamalludin
} Harun ${ }^{a}$, Mohd Nihra Haruzuan Mohamad Saida*, Zaleha Ismaila, Nooraffandy Yahayaa , Fawazul Khair ${ }^{b}$

${ }^{a}$ Department of Education Mathematics, Science and Multimedia Creative, Faculty of Education, Universiti Teknologi Malaysia, Johor Bahru, Malaysia ${ }^{b}$ Department of Architecture, Faculty of Built Environment, Universiti Teknologi Malaysia, Johor Bahru, Malaysia

*Corresponding author: nihra@utm.my

\begin{abstract}
The purpose of the study is to examines the dominant design and learning strategy used by various MOOCs platforms to foster students' Self Directed Learning. Method used in the study was based on the search of relevant literature through online database such as IEEE Explore, ProQuest, ScienceDirect and ResearchGate. The keywords in the search for the relevant literature include MOOCs and learning strategy, MOOCs and design strategy, MOOCs and Self Directed Learnig. The result of the meta-analysis revealed that the most frequently used learning strtegies by the various MOOCs platforms are the social construcvist and peer-to-peer approach to learning. These two strategies are found to be related to cMOOCs and xMOOCs. Similarly, of all the designs the dominant design strategy use by MOOCs providers is cMOOC and partially the blended or hybrid MOOCs. The study revealed the dominant learning strategies employed by MOOCs platforms. This may help other MOOCs designers to give emphasis to the use of best learning strategies and perhaps improve on the existing ones. The findings may also have implication to students willing to acquire knowledge through MOOCs to choose the appropriate instruction strategy that will Foster SDL.
\end{abstract}

Keywords: cMOOC; xMOOC; blended MOOC; self-directed learner; meta-analysis

(C) 2017 Penerbit UTM Press. All rights reserved

\subsection{INTRODUCTION}

Massive Open Online Courses are new trends in the field of education and al technology that promotes learning online by several universities across the world [1]. It seems to have taken a center stage across many disciplines. It has been offered freely in many leading universities and by some open education resources [1]. Additionally, there are other platforms that provide MOOCs across the world, popular among them are: Udacity, FutureLearning, OpenLearning, Coursera, edX, Udemy, and Khan Academy. MOOCs has come into forefront in 2012 when the media gave a robust attention to the acronyms [2]. It is pertinent to note here that the idea of MOOCs came to surface as a result of open online courses (OOCs) using web technology, which was introduce by Semens and Downes through the application of connectivism and connection knowledge in 2008 (CCK08).

According to [3] the concept of connectivism and connection of knowledge is not simply about the use of network of diverse technologies but it involves various technologies that are linked together to provide the desired learning outcome. Connectivism as a theory is geared toward autonomy and diversity of network. Knowledge can be acquired through the interaction of different sets of tolos [3]. The theory is considered to be one of the dominant online learning theories that provides a precise description of the inner working condition of the mind [4]. Connectivism could be a process of distributing knowledge across a network of connection [5]. This theory of learning might provide learners with an insight in to their learning skills and identify task required of them in order to flourish in a digital era [5]. These learning activities are the learners' ability to seek for current information and filter the acquired information [6]. Learning activities in MOOC involves a large scale learning where many students enrolled to the exercise and MOOCs is carried out in a blended learning form to a small number of students in a class in school campus. These has been classifies under online learning activities [7].

Therefore, MOOC can be classified into two major categories. The major MOOCs models are cMOOCs and xMOOCs. The concept of cMOOCs is derived from the connectivist learning theory, cMOOC stands for connectivist MOOCs. This theory centrally deals with pedagogical model of peer learning [8]. The underlying assumption that governs the cMOOCs is that it is specifically focused on knowledge construction with reference to social network learning and autonomy while xMOOC is deduced from behaviorist theory of learning. The $\mathrm{XMOOC}$ is closely related to the traditional teaching setting which mainly involve duplication and disseminating of knowledge [2]. This model also deals with the online version of learning and a face to face interaction between student and a tutor; this usually carried out through discussion and lecture. In this model the students have direct interaction with tutor and there is evident that xMOOCs is mainly offered in many of the MOOCs offered by Coursera, Udacity, and others [9]. However, the current practice combines the two models which is called as blended or hybrid MOOCs. This design is aimed at allowing students to choose from multiple pathways through the content and activities $[10,11]$. Blended MOOCs is believes to have improves students' retention rate and shorten time-todegree and equally it improves quality of content and of the course [11].

MOOCs are aimed at large scale participation and open access via Internet. The openness of MOOCs requires no protocol to access, users do not need to a registered student from any formal school set up and mostly participants were allowed to enroll to the program freely. Any student that is willing to participate will be allowed to take part in the course. Despite it openness, there are some challenges face by providers of the open education resources.

One of the fundamental problem faced by MOOCs providers is the massive drop-out rates [5]. Student retention and participation rate in MOOC are gradually reducing in some quarters [7]. Despite, it popularity and acceptance, there are factors that led 
to the dropout among students. Some of the factors may include the evidence of no penalty for entry or exit and coping with different learner learning styles. Interestingly, there are large number of learners in MOOCs which might attract students with different learning styles from all over the world [1]. This may pose a challenge to MOOCs designers, because without considering different learner learning styles, MOOCs may suffer massive learner dropout. Thus, it might be necessary to consider developing an appropriate MOOCs design that could help accommodate learners with different learning styles from different background. This meta-analysis, therefore, seeks to examines the dominant design and learning strategies employed in MOOCs platforms which promotes learners SDL.

There are quite a number of MOOCs providers, which are found across the world. But, indicators show that most of the successful MOOCs were found in the United States and some parts of European countries. Apparently, universities in the United States do engaged in a large scale MOOC where thousands of participants register for an online course [12]. MOOCs attained its prime days when most premier universities (Harvard, MIT, Stanford) decided to fully participate in MOOCs [1]. Noticeably, most of these institutions provide MOOCs for free and it is open to all. However, the institutions issue certificate only on payment with virtually no credit [7]. MOOCs platform such as edX, Coursera and Udacity are believe to be the three most popular online platform that host MOOCs. The first is a non-profit making ventures. In this platform students were allowed to register for a free online courses. In contrast, Coursera and Udacity charge student enrollment fee for online courses. The edX is own by MIT and Harvard in march 2012 and began with over 155, 000 students registered for 6.002x course which comprises of lecture, discussion forum and online collaboration elements [12]. The papers were analyzed base on the collections different articles on MOOCs design. Thus, the research questions that guide this study was quantitatively summarized.

\subsection{RESEARCH QUESTIONS}

This meta-analysis was conducted to examine the existing MOOCs designs. The study is aimed at examine the design and learning strategies use in MOOC platforms that promotes learner SDL. In this regard, the paper seeks to answer the following research questions.

- What are the dominant design strategies of Massive Open Online Courses (MOOCs) in higher education?

- How can learning strategies of Massive Open Online Courses (MOOCs) foster SDL?

\subsection{METHODOLOGY AND ANALYSIS}

\section{Data Collection and Analysis}

Relevant studies were located through a comprehensive search of publicly available literature published from 2012 through July 2015. We chose 2012 as a starting point for the literature search because MOOC was first introduced in 2008 and emerged as a popular mode $\mathrm{f}$ learning in 2012. The following data sources and search tools were used: (1) electronic research databases, including IEEE Explore, ProQuest, ScienceDirect, ResearchGate, ScienceDirect, PubMed, Wiley Online Library and Taylor \& Francis Online. Search strategies were adapted to fit the tool used, but all searches were conducted with combinations of three types of search terms, one is Massive Open Online Course learning platform (e.g., OpenLearning, edX, Coursera, Khan Academy, Open2Study), second term is a design and third term is learning strategies used (2) articles published since 2012 in the following key journals: Australasian Journal of Educational Technology, Journal of Distance Education (Canada), Distance Education (Australia), and International Review of Research in Distance and Open Education, (3) the Google Scholar search engine with a subset of the search terms used in the electronic research data- bases. All the articles were retrieved digitally and the related studies design and learning strategies in MOOC. During the initial stage, there was no limitation on searching relevant studies, all concept papers, research papers, conference and government reports. Therefore, the search found a total of 21 papers but there were only 14 papers related with our research objectives. During the second stage, the number of articles were analyzed into two categories which are meta-analysis on content evaluation and learners perception.

Table 1 sumarizes the meta-analysis undertaken to clarify existing platform of MOOC use in instruction and provide information concerning design factors that would be helpful to educational administrators. A meta-analysis technique was used to synthesize the results of eight independent studies. Variables analyzed included characteristics of design approach, learn ing strategy and platform used.

Among the eight studies analyzed to consider the design approach and learning strategies on content evaluation in MOOCs, the most captivating designs were found to be cMOOCs and XMOOCs, these designs appeared in four distinct studies, indicating frequent application by MOOCs providers. This does not finalized that other forms of MOOC are not applying similar designs, they do but this study is resting it judgment on the eight studies adopted in the search engines, found to be relevant for this study. Thus, the hybrid MOOCs, is the combination of both xMOOCs and cMOOCs, it appeared in three different platforms in the table below. Moreover, the learning strategy employed in content evaluation in MOOCs was scattered across but peer-to-peer strategy is slightly considered to be found in two or three studies and other strategies that spread across are the teacher-to-peer, Blended learning, Flipped classroom, Brain wiring, and Team-Based Learning. The most appeared platform in the table above is Coursera, it appeared in four distinct studies. Both edX and Open Learning appeared in two studies. This indicates that Coursera is dominant over other platforms in terms of content evaluation in MOOCs 
Table 1 Analysis on design approach and learning strategies platform regards of content evaluation in MOOC

\begin{tabular}{|c|c|c|c|c|c|}
\hline No. & Studies & Paper Title & $\begin{array}{l}\text { Design } \\
\text { Approach }\end{array}$ & Learning Strategy Variable & Platform \\
\hline 1 & {$[10]$} & $\begin{array}{l}\text { Lessons Learned While Designing and } \\
\text { Implementing a Multiple Pathways } \\
\text { xMOOC + cMOOC }\end{array}$ & $\begin{array}{l}\mathrm{xMOOC} / \\
\mathrm{cMOOC}\end{array}$ & $\begin{array}{l}\text { the combination of the principles of } \\
\text { instructor-centric transmission of } \\
\text { knowledge with the principles of } \\
\text { learner-centric connectivist interaction, }\end{array}$ & edX \\
\hline 2 & [13] & $\begin{array}{l}\text { Instructional Strategies And Challenges } \\
\text { In MOOCs. }\end{array}$ & $\begin{array}{l}\mathrm{xMOOC/} \\
\mathrm{cMOOC}\end{array}$ & Blended learning & Coursera \\
\hline 3 & [14] & Evaluation of Malaysia Pilot MOOC & $\begin{array}{l}\text { hybrid } \\
\text { MOOC }\end{array}$ & Flipped Classroom & OpenLearning \\
\hline 4 & {$[15]$} & $\begin{array}{l}\text { The Transformative Potential of } \\
\text { Blended Learning Using MIT edX's } \\
\text { 6.002x Online MOOC Content } \\
\text { Combined with Student Team-Based } \\
\text { Learning in Class }\end{array}$ & $\begin{array}{l}\text { hybrid } \\
\text { MOOC }\end{array}$ & $\begin{array}{l}\text { Team-Based Learning and flipped } \\
\text { classroom }\end{array}$ & edX \\
\hline 5 & [16] & $\begin{array}{l}\text { Teaching entrepreneurship using } \\
\text { Massive Open Online Course (MOOC) } \\
\text { Review }\end{array}$ & $\begin{array}{l}\text { hybrid } \\
\text { MOOC/ } \\
\text { xMOOC }\end{array}$ & Brain Rewiring & OpenLearning \\
\hline 6 & [17] & $\begin{array}{l}\text { Motivation to learn in massive open } \\
\text { online courses: Examining aspects of } \\
\text { language and social engagement }\end{array}$ & cMOOC & peer-to-peer collaboration & Coursera \\
\hline 7 & {$[18]$} & $\begin{array}{l}\text { Students' patterns of engagement and } \\
\text { course performance in a Massive Open } \\
\text { Online Course }\end{array}$ & $\begin{array}{l}\text { pMOOC } \\
\text { (project based } \\
\text { MOOC) }\end{array}$ & Peer assesment and self assesment & Coursera \\
\hline 8 & [19] & $\begin{array}{l}\text { MOOC Pedagogy: Gleaning Good } \\
\text { Practice from Existing MOOCs }\end{array}$ & $\begin{array}{l}\text { xMOOC/ } \\
\text { cMOOC }\end{array}$ & Peer-to-peer teaching & Coursera \\
\hline
\end{tabular}

Meanwhile Table 2 displays the meta-analysis undertaken to clarify existing platform of MOOC use in instruction and provide information concerning students perception that would be a developing indicator of good pedagogy that can be used reliably in a MOOC platform. A meta-analysis technique was used to synthesize the results of five independent studies. Variables analyzed included characteristics of design approach, learning strategy and platform used. Learner perspective $s$ is considered to be the focal point of any instruction. In this table, the design approaches applied in the five (5) studies was found to be cMOOCs, virtually it appeared in all the five studies under consideration. This shows that cMOOCs is considered to be more practicable in terms of learners' perspectives. Though, xMOOCs, which is considered to be less learner approach, was equally found to be applicable in three out of the five studies. More so, the learning strategy variables used in determining learner perspectives indicated peer-to-peer teaching with two appearance and collaborative techniques was also cited in two studies. Therefore, the platform that considered learner perspectives is scattered across.

Table 2 Analysis on design approach and learning strategies platform of learner's perspectives in MOOC

\begin{tabular}{|c|c|c|c|c|c|}
\hline No. & Studies & Paper Title & $\begin{array}{c}\text { Design } \\
\text { Approach }\end{array}$ & Learning Strategy Variables & Platform \\
\hline 1 & [20] & $\begin{array}{l}\text { The Death of the Large Lecture Hall, } \\
\text { the Rise of Peer-to-Peer Course } \\
\text { Delivery? }\end{array}$ & $\begin{array}{l}\text { cMOOC } \\
\text { xMOOC }\end{array}$ & peer-to-peer teaching & Coursera \\
\hline 2 & [21] & $\begin{array}{l}\text { Designing an Effective Massive Open } \\
\text { Online Course for Educators: } \\
\text { Evidence from Student Experience }\end{array}$ & cMOOC & peer-to-peer teaching & $\begin{array}{l}\text { Open Learning Network } \\
\text { learn.canvas.net }\end{array}$ \\
\hline 3 & [22] & $\begin{array}{l}\text { Developing a Computer Programming } \\
\text { MOOC }\end{array}$ & $\mathrm{xMOOC}$ & $\begin{array}{l}\text { Collaborative team-based } \\
\text { methodology }\end{array}$ & edX \\
\hline 4 & [23] & $\begin{array}{l}\text { Building for massive scalability: the } \\
\text { production case of an astronomy } \\
\text { MOOC }\end{array}$ & $\begin{array}{l}\text { cMOOC } \\
\text { xMOOC }\end{array}$ & $\begin{array}{l}\text { cognitive-behaviorist, pedagogy } \\
\text { and interactions. }\end{array}$ & Open2Study \\
\hline
\end{tabular}

Based on the analysis and literature citations shown in Table 3, researchers have lists the major components and more frequently noted by previous researchers as learning strategies factors that supported SDL in MOOCs among them are (1) problem based leaning; (2) social constructivist; (3) team-based learning; (4) Flipped classroom (5) brain rewiring (6) project based model assessment (7) peer-topeer approach (8) collaborative peer review. Basically, of the eight (8) learning strategies cited in this table only two were found to appeared frequently that support students' SDL in MOOCs. The social constructivist and peer-to-peer approach are the two dominant strategies in the studies under consideration. The cMOOCs is most often built on social constructivist, which is why is visibly appeared in almost all the design approach, likewise peer-to-peer is also found to be embedded to both xMOOCs and xMOOCs platforms. Base on the above, the study would critically discuss on the dominant strategies that support learners learning strategies through the new technology for teaching and learning. 
Table 3 Comparison of learning strategies constructs based on document analysis

\begin{tabular}{|c|c|c|c|c|c|c|c|c|}
\hline Learning & 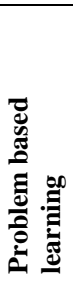 & 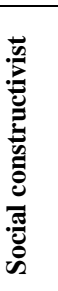 & 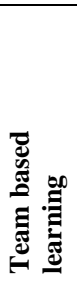 & 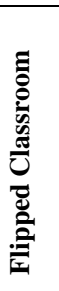 & 䓪 & 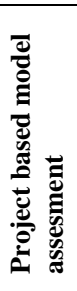 & 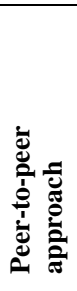 & 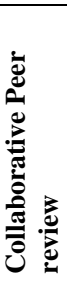 \\
\hline [10] & $\checkmark$ & $\checkmark$ & & & & & & \\
\hline $\begin{array}{l}{[13]} \\
\end{array}$ & & $\checkmark$ & & & & & & \\
\hline [14] & & $\checkmark$ & & $\checkmark$ & & & $\checkmark$ & \\
\hline [15] & & & $\checkmark$ & $\checkmark$ & & & & \\
\hline [16] & & & & & $\checkmark$ & & & \\
\hline [17] & & $\sqrt{ }$ & & & & & $\checkmark$ & \\
\hline [18] & & & & & & $\checkmark$ & $\checkmark$ & \\
\hline [19] & & $\checkmark$ & & & & & $\checkmark$ & \\
\hline [20] & & & & & & & $\checkmark$ & \\
\hline [21] & & $\checkmark$ & & & & & $\checkmark$ & \\
\hline [22] & & & $\checkmark$ & & & & & \\
\hline [23] & & $\checkmark$ & & & & & & $\checkmark$ \\
\hline
\end{tabular}

\subsection{RESULTS AND DISCUSSION}

The main aim of this study was to obtain information about design that dominate the new technology system MOOC and learning strategies that can support learning. Thus, the meta-analysis below sheds light on the findings of dominant design strategies and best learning strategies that support learners learning.

\section{Category 1: Learning Strategy via Group Based Learning}

According to a meta-analysis that compared online pedagogies in MOOC learning environment, it was found that group based learning share common features that learning is a process of team based learning, problem based learning, collaborative teaching and peer interaction ([10], [13], [14], [17], [19], [21], and [23]). MOOCs group based learning built on connectivist principles, the focus of the course was building networks of individuals rather than an instructor delivering content. Unlike individual learning, group based learning may encourage learners to work together. This suggest that group based learning may foster SDL, engage learners and motivating their team members.

The degree of student motivation in learning online has played an important role in evaluating the effectiveness of MOOC. A meta-analysis of 3 articles reporting student motivation with MOOC indicated that there was a correlational relationship between learners' patterns of participation with their MOOC performance: learners who demonstrated active engagement tended to outperform the ones who did not prioritize a similar trait ([17] and [18]). This finding may suggest that when comparing between MOOC completers and non-completers, findings indicated an increase in completers' motivation to learn and a decreased in the motivation of noncompleters.

Some xMOOCs have experimented with assigning students randomly to small groups for peer assessment, especially for more open-ended or more evaluative assignment questions in a peer to peer teaching. Based on the meta-analysis of the three articles ([19]; [21] and [11]) satisfied the criteria of peer-to-peer teaching as a best learning strategies to foster SDL. The criteria include thoughtful integration of peer assessments into coursework were able to enhance students' learning in a number of ways as it helps build trust and intellectual community; it leads to more thoughtful and reflective discussions; and it can help students cultivate a greater capacity for critical and evaluative judgment.

The meta-analysis results indicated that, a combination of instructional support mechanism and social connectivsm should involve cohesively in creating a coherent learning environment. The two different pedagogical approaches in the framework of xMOOC as well as cMOOC would encourage SDL in MOOC platform.

\section{Category 2: Learning Strategy via Blended Learning}

Blended learning is that form of formak education program in which learing is taking place path through online amd face-to-face instruction, content delivery with some element of student having control over time and place [24]. Blended learning can support a variety of learning processes. Instrcutors and learners in a traditional classroom are allowed to meet on face-to-face [25], thus, face-to-face interaction allow with other learning strategies like problem solving, team building, collaborative learning, and culture building. These methods can be effectively used in a MOOCs setup to enhance teaching and learning. It has become evidence that MOOCs has become a central point of discussion, as a result of new horizon of innovations in the field of educational technology various MOOCs platforms had emerged.

The spread of new technology has greatly increase online and face-to-face instructions employed by various MOOCs platforms [26], blended learning approach combines the best elements of face-to-face and online learning, It has now become norm in large enterprises like MOOCs platform by providing variety of instructions to learners' through delivering training to large number of 
students of diverse population [25]. These and many others may pose challages and prospects in this new platform. Therefore, this study study is aimed at analyzing the learning strategies and design use in MOOCs platform.

There is a need to look more closely at whether there are any factors causing MOOC student dissatisfaction, frustration, or anxiety. For the purpose of this research, previous studies on students evaluation on learning content related to collaborative learning and social presence were reviewed. [22] used a collaborative based-team methodology as a pedagogical approach in designing a Mooc, where the understanding of the fundamentals of programming and the consolidation of its philosophy was the main object of this course. Using this approach to investigate the strength, perspectives and the opportunities of collaborative strategy, within a case study of computer programming course to designing a Mooc through the integration of a multidisciplinary team of professionals and nonprofessionals and collaborating in each phase of creating the Mooc; analysis, designing, development, implementation, and evaluation phase Regarding learning content and collaborative learning, [10] found that the majority of participants in their study rated their blended learning experiences as good or excellent. Similarly, [13] reported that students who participated in online blended learning tasks expressed higher levels of satisfaction with their learning process compared to those who engaged in just face-to-face classroom session.

\section{Category 3: Learning Strategy via Flipped Classroom}

Flipped Classroom gives attention to active learning through the use of $\mathrm{MOOC}$ as an intermediary in learning and teaching. In addition finding the dominant learning strategies, previous study have reported important factors in identifying the dominant learning strategies which is flipped classroom. Previous studies on student satisfaction related to flipped classroom was reviewed. [27]opined that flipped classroom involve lots of activities ranging from problem solving, concept maps, Problem Based Learning, and case studies, in this from of learning, students generally work in group of 2 or 3 to provide answers to problems on an individual basis. Regarding student satisfaction and flipped learning, [14], shown high levels of student satisfaction with the flipped classroom, in comparison with traditional lecture-based courses Similarly, [15], reported that students who participated in team based learning together with flipped classroom activities performed better to compare with the traditional approach. The finding resulted in measuring the effectiveness of the team based learning together with flipped classroom in improving the retention and understanding of information. Conversely, a flipped classroom together with face-to-face interaction can make a dramatic improvement in student learning and it can accommodate large group of learner with different backgrounds [13, 28]

According to [29], a flipped learning model has a positive impact on student learning outcome, over $80 \%$ of students were reported to have improve on their level of mastery of information, tertention of information, and attitude toward learning after filipping in class. To flipped a classromm is a quantifiable task because it may involves extra time and energy, where the instructor have the opportunity to walk around the class and listen to student opinion and concern [27]. Flipping classroom can result in significant learing achievement by making the student to develop a positive attitude towards learning processes. Major ity of large classroom have agreed that flipping their classroom have a positive influence on their performance in class [27]. Flipping in MOOCs can help boost students learning and experience toward specific skills [29]. MOOCs provide opportunities to cover wide range of flexible approach toward curriculum design like flipped classroom and blended le arning [30].

\section{Category 4: Learning Strategy via Brain Rewiring}

There are many innovative teaching and learning strategies that support approaches to online learinng. These may include problem base learinng, collaborative strategies, face-to-face, and brain rewiring. Brain rewiring in an online platform like MOOCs is meant to develop a self-motivation, optimism, and adaptability [31]. [16] Conducted a qualitative research indicated that students felt overwhelming gratitude, happiness and satisfaction with the lecturer, lecture quality and production as well as brain rewiring activities. In the study explained the impact of "Brain Rewiring" activity when offered within a MOOC could be attributed to the fact that the MOOC allowed the creation of a supportive learning community in which students encourage and inspire each other to see the positive side of life. Furthermore, this attribute may strengthen students to develop comfident in their learning process, this is because a motivated student may easily have zeal to become self-suffiecient and perhaps become learner who will regulate his or her learing process. In order word, when a brain rewiring was instill on a student, it can simply regulate students' faculty of thinking, which might lead them to think independently in terms of learning speed, equally it may foster self-directed learning.

\subsection{CONCLUSION}

This study provided a snapshot on design approach and learning strategies platform of learner's perspectives in MOOC. Typically, MOOC strategies platform applied learning strategies with four categories namely group based learning, blended learning, flipped clasroom, and brain rewiring. These strategies involved basic steps as a guide to design an effective MOOC. Based on the results, group based learning was the most effective strategy to implement in MOOC. Most of the design approach of studies were focused on cMOOC. While the most common platform was OpenLearning and Coursera.

\section{References}

Chen, X., D.R. Barnett, and C. Stephens. (2013). Fad or Future: The Advantages and Challenges of Massive Open Online Courses (MOOCs). In Research-To Practice Conference In Adult And Higher Education.

Ping, W. (2013). The Latest Development and Application of Massive Open Online Course: From cMOOC to xMOOC [J]. Modern Distance Education Research, 3(005).

Downes, S. (2008). Places to Go: Connectivism \& Connective Knowledge. Innovate: Journal of Online Education, 2008. $5(1)$, 6.

Downes, S. (2006). Learning Networks and Connective Knowledge. Collective Intelligence and Elearning, 20, 1-26.

Downes, S. (2007). What Connectivism Is. Online Connectivism Conference: University of Manitoba.

Kop, R. and Hill, A. (2008). Connectivism: Learning Theory of the Future or Vestige of the Past? The International Review of Research in Open and Distributed 
Learning, 9(3).

Ng, A. and Widom, J. (2014). Origins of the Modern MOOC (xMOOC). Hrsg. Fiona M. Hollands, Devayani Tirthali: MOOCs: Expectations and Reality: Full Report,2014: p. 34-47.

Haggard, S., et al. (2013). The Maturing Of The MOOC: Literature Review Of Massive Open Online Courses And Other Forms Of Online Distance Learning. Department for Business, Innovation and Skills, UK Government.

Waard, I., et al.. (2014). Challenges for Conceptualising EU MOOC for Vulnerable Learner Groups. Proceedings of the European MOOC Stakeholder Summit 2014, 33-42.

Crosslin, M. and Dellinger, J. T. (2015). Lessons Learned While Designing and Implementing a Multiple Pathways xMOOC+ cMOOC. In Society for Information Technology \& Teacher Education International Conference.

Morrison, L., et al. Co-Constructing Knowledge Through mOOC Design and Development. In Proceedings of Society for Information Technology \& Teacher Education International Conference.

Breslow, L., et al. (2013). Studying Learning in the Worldwide Classroom: Research into edX's First MOOC. Research \& Practice in Assessment, 8, 13-25.

Chew, L.K. (2015). Instructional Strategies and Challenges in MOOCs. Advances in the Scholarship of Teaching and Learning, 2(1), 41-50.

Habibah Ab Jalil, et al. (2016). Evaluation of Malaysia Pilot Mooc (Final Report). Universti Putra Malaysia: CADe UPM: Serdang.

Ghadiri, K., et al. (2013). The Transformative Potential of Blended Learning Using MIT Edx's 6.002 X Online MOOC Content Combined with Student TeamBased Learning in Class. Environment, 8, 1-15.

Al-Atabi, M. and J. DeBoer. (2014). Teaching Entrepreneurship Using Massive Open Online Course (MOOC). Technovation, 34(4), 261-264.

Barak, M., Watted, A., and Haick, H. (2016). Motivation to Learn in Massive Open Online Courses: Examining Aspects of Language and Social Engagement. Computers \& Education, 94, 49-60.

Phan, T., S.G. McNeil, and B.R. Robin. (2016). Students' Patterns of Engagement and Course Performance in a Massive Open Online Course. Computers \& Education, 95, 36-44.

Barnett, J., McPherson, V., and Sandieson, R. M. (2013). Connected Teaching and Learning: The Uses and Implications of Connectivism in an Online Class. Australasian Journal of Educational Technology, 29(5), 685-698.

Navarro, P. (2015). The Death of the Large Lecture Hall, the Rise of Peer-to-Peer Course Delivery? American Journal of Distance Education, 29 (4), $260-268$.

Banister, S., Reinhart, R., and Ross, C. (2015). Designing an Effective Massive Open Online Course for Educators: Evidence from Student Experience. In Society for Information Technology \& Teacher Education International Conference.

Spyropoulou, N., et al. (2015). Developing a Computer Programming MOOC. Procedia Computer Science, 65,182-191.

Ostashewski, N., Matoane, M. and Mashile, E. O. (2013). Building for Massive Scalability: The Production Case of an Astronomy MOOC. In World Conference on E-Learning in Corporate, Government, Healthcare, and Higher Education.

Bailey, J., et al. (2013). Blended Learning Implementation Guide. Version 1.0.

Woodall, D. (2010). Blended Learning Strategies: Selecting the Best Instructional Method. White Paper: Skillsoft.

Watson, J. (2008). Blended Learning: The Convergence of Online and Face-to-Face Education. Promising Practices in Online Learning. North American Council for Online Learning.

Stone, B.B. (2012). Flip Your Classroom to Increase Active Learning and Student Engagement. In Proceedings from 28 th Annual Conference on Distance Teaching \& Learning, Madison. Wisconsin, USA.

Veronica, D., Malcolm B., and Pelletier, S. (2013). Learning and the Massive Open Online Course. EDUCAUSE Learning Initiatives.

Yarbro, J., et al. (2014). Extension of a Review of Flipped Learning. Pearson.

Hayes, S. (2015). MOOCs and Quality: A Review of the Recent Literature. QAA MOOCs Network.

Al-Atabi, M. (2016). Is Education Making our Students Less Emotionally Intelligent? Holistic Education and Developing Emotional Intelligence using MOOCs. In Digital Inclusion: Transforming Education Through Technology. MIT Cambridge, Massachussets, USA: LINC. 